there is some extremely good journalism being produced here, whether it is long form reporting by people like Nicky Hager, good local affairs coverage by the country's surviving weeklies, the presence of Māori Television and the survival of Tagata Pasifika.

Bunce's analysis of the malaise in the New Zealand media is accurate and the solutions she offers timely. In a time of crisis it is more important than ever to fix New Zealand's media system before it is too late. - PHILIP CASS is reviews editor of Pacific Journalism Review.

\section{Lockdown sanity and survival in the age of Zoom}

\section{Lockdown Lawyers - A Collection of COVID-19 Poetry, by Emma Trevett and Jon Whitfield QC (eds). London, UK: Legal Action Group, 2020.96 pages. ISBN 9781913648008}

I ACCEPTED the invitation from my son in law (a barrister in London) to contribute to this anthology, with an antipodean poem I had written reflecting on COVID-19 and ANZAC day 'They shall grow. .' When the anthology, commissioned as a fundraiser for a particularly vulnerable group during the pandemic, came out, I was simultaneously delighted, honoured, enlightened, angered, saddened, and then amused by the whimsy of some of the poems in the collection.

I grew up in an immigrant family in New Zealand and I lived with their English experiences and memories of the blitz in London. So the distance,

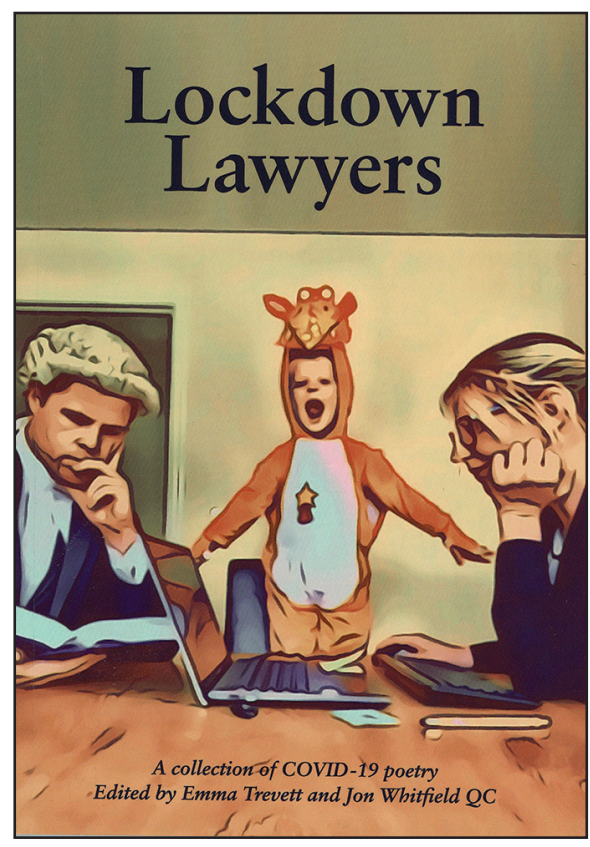

and yet closeness, of my daughter and her London family, in the plague-like years revisited of COVID-19, resonated strangely. With my own research focusing on software and global virtual teams, the ubiquity of Zoom and the 'near yet far' ersatz experience of 'connecting' online in a time of uncertainty and anxiety had a poignant aspect.

Particular poems speak to us of these distant connections, such as one from a lawyer's small London flat pining for the luxury of a bookcase to furnish the backdrop of a Zoom meeting. There is also one about a lawyer in (virtual) court having a client defended over Skype, sent down for a first offence and then closing the laptop to forget about it.

To gain a window into the lives of a group of legal aid lawyers and their families in a time of COVID-19 and how 
a particular professional group maintained a sense of sanity and survival was truly special. I have a sense that this collection will stand as an enduring testimony of the power of the human spirit against adversity. It also speaks to how interconnected and interdependent we all are and how a group of people quietly caring on the other side of the world can echo so powerfully! - DR TONY CLEAR is associate professor with the Software Engineering Research Lab at Auckland University of Technology.

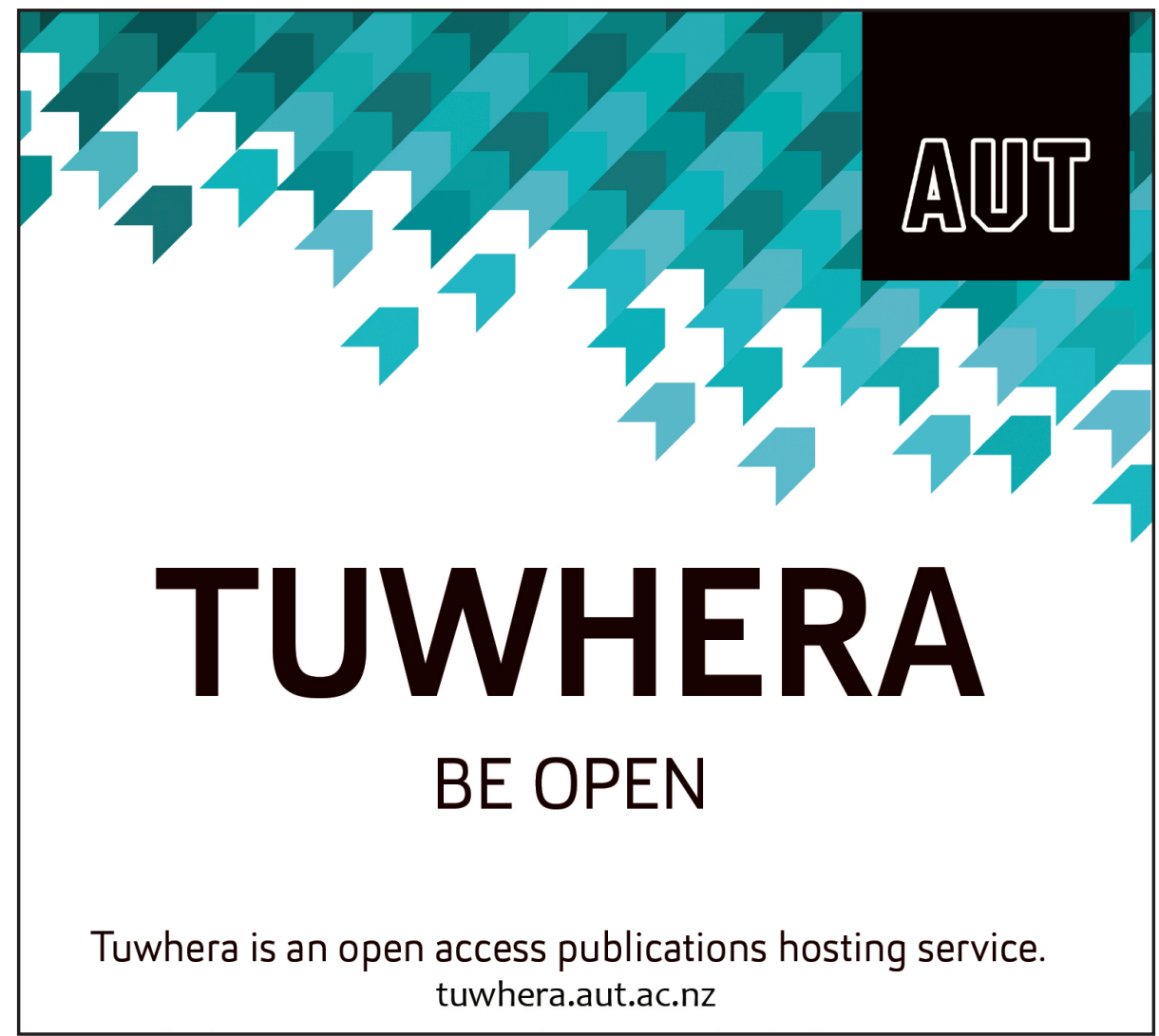

304 PACIFIC JOURNALISM REVIEW 26 (2) 2020 